\title{
基于多组学水平的动物分子趋同演化研究新进展
}

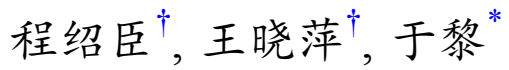

云南大学省部共建生物资源保护与利用国家重点实验室\&生命科学学院, 昆明 650091

$\dagger$ 同等贡献

* 联系人, E-mail: yuli@ynu.edu.cn

收稿日期：2019-06-13; 接受日期：2019-06-19; 网络版发表日期：2019-07-08

国家自然科学基金(批准号: 91731311, 31760619)和云南省教育厅科学研究基金产业化培育项目 (批准号: 2016CYH02)资助

摘要表型趋同的分子证据探索一直是趋同演化研究的热点. 高通量测序带来的多组学数据为分子趋同演化提 供了大量研究材料和更加多样的研究角度. 分子趋同的概念和研究方法也从编码基因的氨基酸替换趋同扩展到 基因丢失趋同、表达调控趋同、表达模式趋同、肠道微生物趋同等多个不同分子层级。本文对近年来基因组时 代下基于多组学水平的分子趋同演化研究的新进展进行综述, 并对该领域未来研究方向进行了展望.

关键词 趋同演化, 基因组趋同, 表达调控趋同, 肠道微生物趋同

趋同演化(convergent evolution)是指物种演化过 程中，进化关系很远的生物类群，在相同的生活环境 或者相同的选择压力作用下产生功能相同或者相似的 形态结构, 如相似的表型特征或行为特征, 或者独立演 化出结构和功能十分相似的器官，这些表型称为趋同 表型(convergent phenotypes) ${ }^{[1 \sim 3]}$. 自Darwin时期起, 趋 同演化就被生物学家视为生物适应环境的重要证 据 ${ }^{[4,5]}$, 蝙蝠和鸟类的前肢分别演化出具有飞行能力的 翅膀 ${ }^{[6] ;}$ 鲸类和鱼类分别演化出适合游泳的鯺与流线 型的外形 ${ }^{[7]}$; 有袋类的袋狼和胎盘类哺乳动物的食肉 目犬科动物分别演化为占据相似生态位的捕食者 ${ }^{[8]}$; 哺乳动物中管齿目(Tubulidentata)土豚、鳞甲目(Pholidota) 穿山甲和披毛目(Pilosa)食蚁兽独立演化出食蚁 的特殊食性 ${ }^{[9]}$ 等.

研究趋同演化这种特殊的自然现象不仅有助于了
解生物适应性机制及生存策略，而且还可以探究生物 演化的可预测性和可重复性 ${ }^{[1 \sim 3]}$. 从分子水平解释形态 上或功能上的趋同演化现象能够将基因型与表型有效 联系起来, 日益成为进化生物学研究领域的一个重要 内容 ${ }^{[2,10]}$, 国内外也有多篇对分子水平趋同演化的研 究综述 ${ }^{[1 ~ 3,11,12]}$. 随着高通量测序技术的快速发展, 利 用大数据和多组学分析方法揭示分子趋同演化机制成 为了研究热点. 分子趋同的概念也从编码基因的氨基 酸替换趋同扩展到基因丢失趋同、表达调控趋同、表 达模式趋同、肠道微生物趋同等多个不同分子层 级 ${ }^{[11,13]}$. 基于不同的研究概念、材料和目的, 分子趋同 的研究方法也在不断地扩展和更新 ${ }^{[14 ~ 19]}$.

本文将对近年来基因组时代下，基于多组学水平 的分子趋同演化研究的新进展进行综述(表1), 并对该 领域未来的研究方向进行展望.

引用格式: 程绍臣, 王晓萍, 于黎. 基于多组学水平的动物分子趋同演化研究新进展. 中国科学: 生命科学, 2019, 49: 874-887

Cheng S C, Wang X P, Yu L. Recent progress in convergent molecular evolution of animals based on multi-omics studies (in Chinese). Sci Sin Vitae, 2019, 49: 874-887, doi: 10.1360/SSV-2019-0101 
表 1 基于多组学水平的动物分子趋同演化研究实例和主要发现

Table 1 Examples and key findings of convergent molecular evolution of animals based on multi-omics studies

\begin{tabular}{|c|c|c|c|}
\hline 趋同表型 & 动物类群 & 研究类别 & 主要发现 \\
\hline $\begin{array}{l}\text { 回声定位 } \\
\text { 系统 }\end{array}$ & $\begin{array}{l}\text { 翼手目蝙蝠; } \\
\text { 鲸偶蹄目齿鲸 }\end{array}$ & 编码基因趋同 & $\begin{array}{l}\text { 对回声定位类群及其姐妹群的 } 22 \text { 个哺乳动物基因组进行比较基因组分析, 检测到 } \\
\text { 回声定位蝙蝠和海豚两个类群间的趋同替换事件, 发现 } 117 \text { 个视力及听力相关蛋 } \\
\text { 白编码基因表现出平行替换信号 }{ }^{20]} \text {; } \\
\text { 利用 } 16 \text { 个哺乳动物基因组进行祖先序列重建, 回声定位蝙蝠祖先仅与齿鲸祖先的 } \\
\text { 趋同基因显著富集到与听力相关的功能基因, 从分子趋同角定位 } \\
\text { 特征的独立起源 }{ }^{[1]} \text {; } \\
\text { 对 } 30 \text { 个胎盘类哺乳动物基因组数据比较分析, 发现 } 4 \text { 个与骨骼肌纤维相关表达基因 } \\
\text { (Casq1, Atp2a1, Myh } 2, M y l) \text { 存在7个保守氨基酸位点的平行替换, 这些基因功能与 } \\
\text { 回声定位类群中高频发声密切相关, 同时新发现三个与的相关基因(Strc, } \\
\text { Tecta, Cabp2)存在平行替换事件 } 22]\end{array}$ \\
\hline $\begin{array}{c}\text { 高海拔极端 } \\
\text { 环境 }\end{array}$ & $\begin{array}{c}\text { 金丝猴属; } \\
\text { 食肉目藏㥿藏土狗; } \\
\text { 偶蹄目藏羚羊、牦牛; } \\
\text { 啮齿目高原鼠兔; } \\
\text { 爬行类沙蜥; } \\
\text { 两栖类倭蛙 }\end{array}$ & $\begin{array}{l}\text { 编码基因趋同; } \\
\text { 肠道微生物趋同 }\end{array}$ & 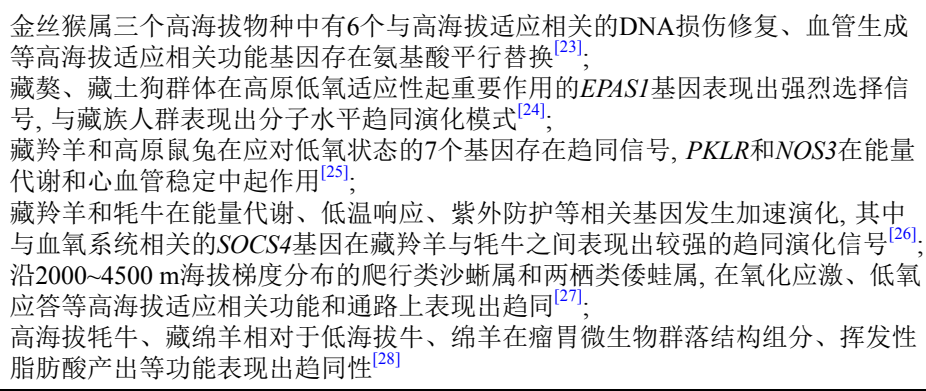 \\
\hline $\begin{array}{c}\text { 地下洞穴极端 } \\
\text { 环境 }\end{array}$ & $\begin{array}{l}\text { 滨鼠科、鼠形鼠科、 } \\
\text { 金毛鼠科、鼠科; } \\
\text { 高原鼠兔、高原鼠鼠、 } \\
\text { 裸鼠鼠 }\end{array}$ & $\begin{array}{l}\text { 编码基因趋同; } \\
\text { 非编码基因表达 } \\
\quad \text { 调控趋同; } \\
\text { 基因表达模式趋同 }\end{array}$ & 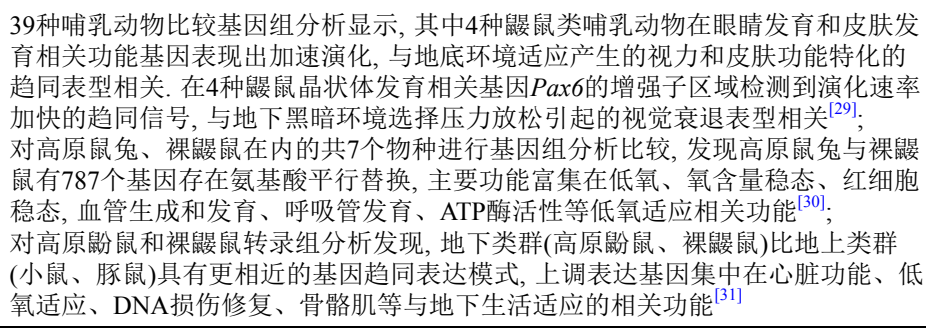 \\
\hline 海洋极端环境 & $\begin{array}{l}\text { 鲸目; } \\
\text { 鳍脚亚目; } \\
\text { 海牛目 }\end{array}$ & 编码基因趋同 & $\begin{array}{l}\text { 通过对三类海洋哺乳动物类群进行基因组分析, 发现其中与骨形成、骨骼肌收 } \\
\text { 缩、甲状腺机能六进、心肌形成、调节血管收缩、调节凝血及脂肪酸氧化等相关 } \\
\text { 的基因发生了氨基酸平行替换, 并受到了正选择作用 }{ }^{[22]} \text { 在统、肌肉功能、 } \\
\text { 皮肤和结缔组织、肺功能、脂代谢等方面发生加速演化 }{ }^{[33]}\end{array}$ \\
\hline 食性趋同 & $\begin{array}{l}\text { 大熊猫、小熊猫; } \\
\text { 海洋哺乳动物; } \\
\text { 蚁食性动物; } \\
\text { 肉食性动物; } \\
\text { 植食性动物 }\end{array}$ & $\begin{array}{l}\text { 编码基因趋同; } \\
\text { 基因丢失趋同; } \\
\text { 肠道微生物趋同 }\end{array}$ & 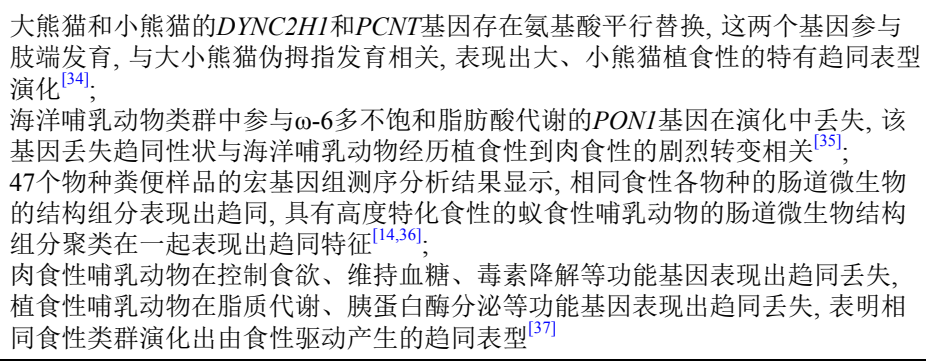 \\
\hline 鸟类飞行能力丧失 & 平胸目走禽类 & $\begin{array}{c}\text { 非编码基因表达 } \\
\text { 调控趋同 }\end{array}$ & $\begin{array}{l}\text { 对 } 9 \text { 个平胸目丧失飞行能力的鸟类在内的共 } 44 \text { 种鸟类进行全基因组分析, 发现非编 } \\
\text { 码区中 } 2355 \text { 个非外显子保守元件(CNEE)在平胸目中发生特异加速演化, 加速演化 } \\
\text { 的CNEE定位在和肢体发育相关的关键基因附近 }{ }^{38]}\end{array}$ \\
\hline 果蝇毛状体缺失 & 双翅目果蝇 & $\begin{array}{c}\text { 非编码基因表达 } \\
\text { 调控趋同 }\end{array}$ & $\begin{array}{l}\text { 果蝇属的两个远缘种 (D. sechellia和D. ezoana) 相较于各自姐妹群物种, 共同表现出 } \\
\text { 幼虫体表毛状体缺失的趋同表型, 是由毛状体生成相关基因 } S v b \text { 上游第3增强子功 } \\
\text { 能缺失而导致 }{ }^{[5]}\end{array}$ \\
\hline 乌贼发光器官发育 & $\begin{array}{c}\text { 夏威夷短尾乌贼; } \\
\text { 剑尖枪乌贼 }\end{array}$ & 基因表达模式趋同 & $\begin{array}{l}\text { 对两种乌贼的眼、脑、鰓、表皮、副缠卵腺等 } 5 \text { 个同源器官及各自独立演化的发 } \\
\text { 光器官进行转录组测序分析, 发现相对于同源器, 官, 不同源的发光器官在基因表达 } \\
\text { 模式表现出较高相似性, 表明其在基因表达水平的趋同特征 }{ }^{[6]}\end{array}$ \\
\hline $\begin{array}{l}\text { 社会性昆虫 } \\
\text { 等级系统 }\end{array}$ & 蚂蚁、蜜蜂 & 基因表达模式趋同 & $\begin{array}{l}\text { 对蚂蚁和蜜蜂的脑部转录组分析发现, 具有相同生殖等级的类群在脑部具有高度 } \\
\text { 相似的基表达模式, 表现出真社会性昆虫(蚂蚁、悹蜂)的等级系统在基因表达水 } \\
\text { 平的趋同演化 }\end{array}$ \\
\hline
\end{tabular}




\section{1 基于编码区基因研究分子趋同演化}

趋同表型是适应性演化的产物，与表型趋同相关 的编码区基因的氨基酸相同替换所引起的蛋白功能发 生相同或相似改变是研究趋同演化的主要机制。根据 预测的祖先位点的差异，编码区基因序列的氨基酸替 换事件分为趋同替换(convergent substitution)和平行 替换(parallel substitution)两种模式 ${ }^{[41]}$. 趋同替换是指 起源于不同祖先的氨基酸独立演化至相同氨基酸，平 行替换是指起源于相同祖先的氨基酸独立演化为相同 氨基酸 ${ }^{[41,42]}$. 在中性演化和纯净化选择作用下, 氨基酸 水平的趋同替换事件比平行替换事件更难发生 ${ }^{[41]}$.

回声定位系统是一类非常特殊的听觉机制, 生物 通过检测物体反射的高频声波，可以在视线不好的环 境中完成定位、导航和捕食等行为, 对动物的生存和 繁殖有重要作用 ${ }^{[43]}$. 在哺乳动物中, 回声定位系统主 要存在于鲸偶蹄目(Cetartiodactyla)和翼手目(Chiroptera)的部分动物类群中, 这两大类群在 90 个百万年前 分歧, 并独立演化出回声定位系统, 是研究趋同演化 的绝佳模型. 早期基于单基因研究发现, 鲸偶蹄目中 的齿鲸和翼手目中的食虫蝙蝠中的多个基因(Prestin, KCNQ4, TMC1, PJVK, Cdh23, Pcdh15, Otof 等)与回声 定位功能相关，会不同程度地影响这些物种的高频听

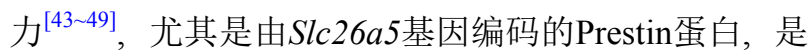
一类在耳蜗外毛细胞表达的马达蛋白，与高频听力显 著相关 ${ }^{[50]}$, 是研究回声定位的明星基因. 通过对回声 定位蝙蝠、齿鲸和其他哺乳动物中的Prestin蛋白的编 码序列进行系统发育分析，发现回声定位蝙蝠和齿鲸 聚在一起，表明两个类群的Prestin基因发生了趋同演 化 ${ }^{[43,49]}$. Liu等人 ${ }^{[21,51]}$ 进一步通过检测Prestin基因在这 两个类群中发生的平行替换位点和功能验证，发现 Prestin蛋白具有在回声定位蝙蝠和齿鲸中都能响应高 频音波的功能，验证了该基因在回声定位类群中表现 出高频听力的功能趋同.

随着基因组测序技术的不断更新和发展，越来越 多生物的基因组被测序，在全基因组水平上篮选和分 析表型趋同相关的分子机制成为新的研究手段和热 点. Parker等人 ${ }^{[20]}$ 首次尝试从基因组水平解析回声定 位复杂性状的趋同分子机制. 研究通过测序两种回声 定位蝙蝠(马铁菊头蝠(Rhinolophus ferrumequinum), 印度假吸血蝠(Megaderma lyra))和两种非回声定位蝙
蝠(黄毛果蝠(Eidolon helvum), 马来大狐蝠(Pteropus vampyrus), 同时结合具有回声定位的宽吻海豚(Tursiops truncatus)构建了共 22 个哺乳动物基因组的数据 集进行基因组水平上的系统发育树分析(图1)，在2326 个直系同源基因中检测到近 200 个基因在回声定位类 群中发生大量氨基酸趋同替换, 其中大部分基因与听 觉、视觉表型相关. Liu等人 ${ }^{[21]}$ 对 16 个哺乳动物基因 组进行分析和祖先序列重建, 发现在回声定位蝙蝠(小 棕蝠(Myotis lucifugus), 大鼠耳蝠(Myotis davidii), 布氏 鼠耳蝠(Myotis brandtii))的祖先枝与回声定位齿鲸(白 暨豚(Lipotes vexillifer), 宽吻海豚(Tursiops truncatus), 虎鲸(Orcinus orca $)$ )的祖先枝的趋同基因中显著富集 到与听力相关功能的基因，但是在与所有鲸类的祖先 枝上并没有检测到与听力相关功能的趋同基因，也从 分子趋同的角度证实了鲸类回声定位独立起源于齿鲸 的祖先. 而Lee等人 ${ }^{[22]}$ 则将研究重点放在回声定位类 群的发声器官, 通过对包含有回声定位系统的小棕蝠 (Myotis lucifugus)和宽吻海豚等30个胎盘类哺乳动物 基因组数据进行全基因组比较分析, 新检测到 3 个与 高频听力的相关基因(Strc, Tecta, Cabp2)发生了平行 替换事件, 4 个与骨骼肌纤维相关的非听觉基因 (Casq1, Atp2a1, Myh2, Myll)存在7个保守氨基酸位点 的平行替换, 这 4 个基因主要在快速抖动的骨骼肌纤维 中表达, 而且在回声定位类群中的转录表达水平显著 高于非回声定位类群，对其中Casq1基因的功能验证 进一步发现小棕蝠和宽吻海豚的Casq1基因在低钲离 子浓度环境下编码固钻多聚体, 为高频发声时肌肉的 快速抖动提供钲离子流, 以此接收高频声波完成回声 定位功能.

虽然基因组层面的分析能够大规模发掘与表型趋 同相关的分子元件，但是同时也会产生大量的假阳性 结果. Thomas和Hahn ${ }^{[52]}$ 以及Rey等人 ${ }^{[53]}$ 对Parker等 人 $^{[20]}$ 的结果中过多的氨基酸趋同替换表示质疑，提出 Parker检测趋同替换的方法中，并没有验证他们检测 到的近 200 个趋同基因在非回声定位类群或近缘类群

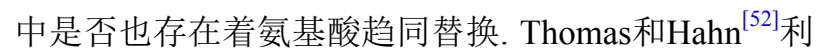
用 6400 个同源基因数据集, 在蝙蝠和牛, 即海豚的姐妹 群, 两个类群中检测到1951个趋同基因, 远高于蝙蝠和 海豚之间的 1372 个趋同基因，且只有 19 个基因与Parker等人 ${ }^{[20]}$ 检测到的趋同基因重叠. Ray等人 ${ }^{[53]}$ 认为, Parker等人 ${ }^{[20]}$ 所用的方法对趋同/平行替换的篮选标准 
A Hypothesis $\mathrm{H}_{0}$ (species tree)

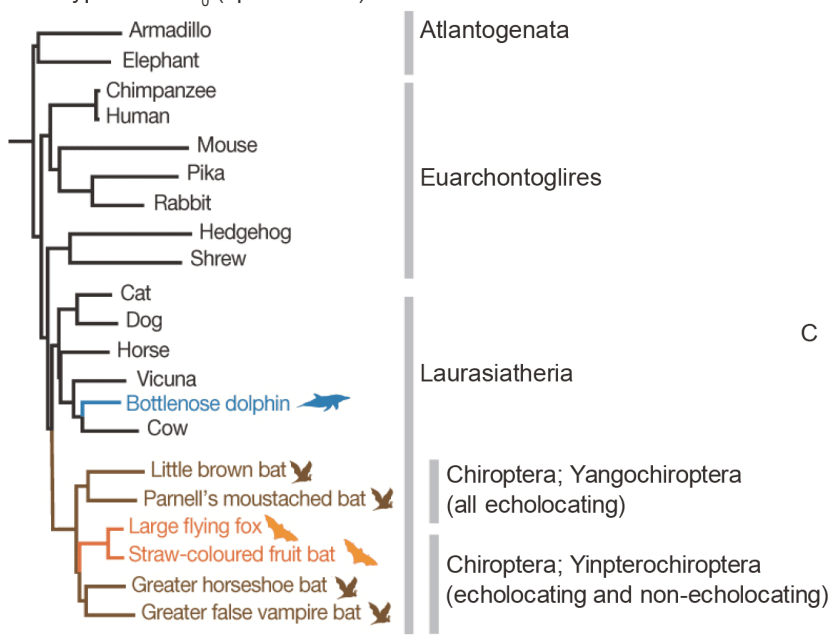

B Hypothesis $\mathrm{H}_{1}$ ('bat-bat convergence')

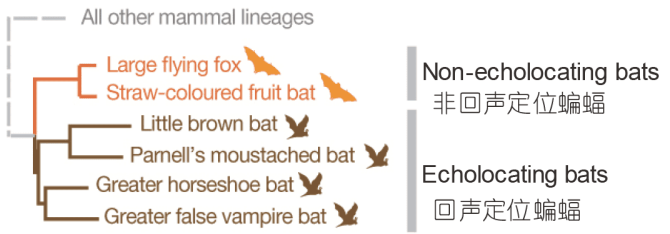

C Hypothesis $\mathrm{H}_{2}$ ('bat-dolphin convergence')

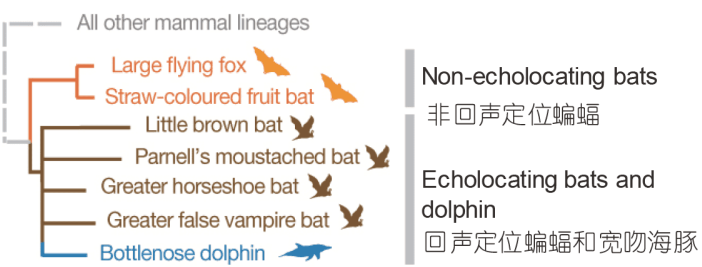

图 1 蝙蝠与海豚系统发育假说. A: 物种树; B: 回声定位蝙蝠类群聚为单系(棕色), 非回声定位的旧大陆果蝠类群聚为一枝 (橙色); C: 回声定位的蝙蝠类群(棕色)和宽吻海豚(蓝色)聚为单系. 引自文献[20]

Figure 1 The phylogenetic hypotheses of bat and dolphin. A: The accepted species phylogeny tree; B: the hypothesis of 'bat-bat convergence', in which echolocating bat lineages (shown in brown) are forced to form a monophyletic group to the exclusion of non-echolocating Old World fruit bats (shown in orange); C: the hypothesis of 'bat-dolphin convergence', in which the echolocating bat lineages and the dolphin (blue) form a monophyletic group to the exclusion of all non-echolocating mammals. Cited from Reference [20]

宽松，导致大量假阳性结果. Zhou等人 ${ }^{[33]}$ 提出使用多 种评估手段来检测多个类群的趋同替换事件以获得更 可靠的结果. Zou和Zhang ${ }^{[17]}$ 发现由于异位显性效果 (Epistasis) ${ }^{[54]}$ 及斯托拉克位移效应(Stokes shift ${ }^{[55]}$ 的影 响，亲缘关系越远的两枝发生相同氨基酸替换的机率 越低，而关系较近的枝系间由于随机替换可能观测到 较多的趋同替换事件，这可以解释Parker等人 ${ }^{[20]}$ 及 Thomas和 $\mathrm{Hahn}^{[52]}$ 观察到的结果. 因此在推断一个基 因是否存在由适应性演化所引发的氨基酸趋同/平行 替换事件时, 需要格外谨慎, 要通过统计学检验观测值 与期望值的显著性来进行进一步的判断.

极端环境压力是生物演化的重要驱动力. 生存在 极端环境，包括高原、地下和海洋等环境的生物，在 面临高紫外线、寒冷、低氧分压等一系列生存压力 时, 会演化出相同或相似的演化策略, 从而产生表型性 状的趋同. 青藏高原由于其高海拔、低氧、低温等极 端环境，对于哺乳动物和人类定居生存是极大的考 验 ${ }^{[56]}$. 家犬作为与藏族人群共同迁移定居在青藏高原 的动物, 表现出与藏族人群相似的低氧适应性. Wang 等人 ${ }^{[24]}$ 对藏獒、藏土狗、中国平原地区土狗和品种 犬 4 个群体进行了全基因组测序和分析, 发现在藏族人 群的高原低氧适应性方面起重要作用的低氧诱导因子
通路中的 $E P A S 1$ 基因 ${ }^{[57,58]}$, 与青藏高原家犬的低氧适 应性也显著相关. 因此, 家犬与人类表现出高原适应 性的分子趋同演化模式.

除了人类及跟随人类活动迁徙和扩散的家养动物 以外, 作为非人灵长类中海拔分布最高的金丝猴属 (Rhinopithecus)物种(猴科(Cercopithecidae), 疮猴亚科 (Colobinae))也是研究高海拔适应的典型范例. 在短短 的 2 个百万年物种分化时间里, 金丝猴属 5 个物种(滇金 丝猴 $(R$. bieti $)$, 怒江金丝猴 $(R$. strykeri $)$, 川金丝猴 $(R$. roxellana), 黔金丝猴 $(R$. brelich $i)$ 和越南金丝猴 $(R$. avunculus))就占据了从低海拔到高海拔(800 4500 m) 的生境类型, 而且有意思的是, 高海拔的三个金丝猴物 种(滇金丝猴、怒江金丝猴、川金丝猴)并没有聚在一 起, 而是分别和低海拔的金丝猴物种(黔金丝猴和越南 金丝猴)有更近的亲缘关系(滇金丝猴和怒江金丝猴与 越南金丝猴聚在一起, 川金丝猴与黔金丝猴聚在一 起 $)^{[59]}$, 因此生活在不同高海拔地区的金丝猴属物种具 有怎样相似的演化机制是一个非常有趣的问题. Yu等 人 $^{[23]}$ 对 5 个金丝猴属物种进行比较基因组学研究，发 现三个高海拔金丝猴物种中有 6 个与高海拔适应相关 的基因存在氨基酸平行替换，这些替换在低海拔金丝 猴属物种和其他哺乳动物中都没有发现. 进一步的群 
体基因组学分析发现，海拔最高的滇金丝猴群体与川 金丝猴中海拔最高的四川/甘肃群体之间共享最多的 与高海拔适应相关的基因.

青藏高原上还有很多土著野生哺乳动物之间也表 现出适应机制的趋同演化. Ge等人 ${ }^{[25]}$ 发现藏羚羊和高 原鼠兔的基因组共享与DNA修复以及ATP酶产生相关 的正选择基因, 其中7个基因在两个类群中发生了趋同 演化，揭示了两个高原物种共同对低氧和高辐射的生 存环境的适应机制. Wang等人 ${ }^{[26]}$ 发现藏羚羊和牦牛的 基因组共有的在能量代谢、低温响应、紫外防护等相 关基因发生了加速演化，其中与血氧系统相关的 $S O C S 4$ 基因在藏羚羊与牦牛之间发生了显著的趋同演 化. 除了哺乳动物, Sun等人 ${ }^{[27]}$ 对爬行类的沙蚚属和两 栖类的倭蛙属高原适应相关的正选择基因进行了比较 基因组学分析，结果发现尽管爬行类和两栖类分化久 远, 但它们依然在氧化应激, 低氧应答通路上表现出 趋同性.

与高海拔环境具有相似环境特点的地下环境也是 研究动物分子趋同演化的良好系统. 地下环境具有持 续黑暗、高二氧化碳和低氧等特点 ${ }^{[60]}$. Davies等人 ${ }^{[61]}$ 对哺乳动物 4 个类群(啮齿目的滨鼠科(Bathyergidae)和 鼠形鼠科(Spalacidae)，非洲猬目的金毛鼠科(Chrysochloridae), 真盲缺目的鼠晏科(Talpidae))共 15 个不同地 下物种进行基因组分析，发现共有的正选择基因主要 富集在与低氧适应相关的血管生成、听觉、嗅觉和皮 肤弹性等通路，而发生氨基酸平行替换的基因则主要 富集在颎面和肾脏发育、精子发育和免疫反应等方 面, 趋同基因与正选择基因之间的重叠基因极少. Davies等人 ${ }^{[61]}$ 认为不同地下哺乳动物更倾向于通过不同 编码区基因的选择适应，而不是通过某个或某些基因 的趋同替换，表现出对地下环境适应的趋同表型. 此 外, Shao等人 ${ }^{[30]}$ 通过比较基因组学方法对地下生活的 高原鼠兔和高原鼠鼠进行检测，共鉴定到787个基因 发生了氨基酸平行替换, 功能主要富集在低氧、氧含 量稳态、红细胞稳态、血管生成和发育、呼吸管发 育、ATP酶活性等低氧适应方面. Partha等人 ${ }^{[29]}$ 比较了 39 个哺乳动物 18980 个同源编码基因的相对演化速率, 在不同鼠鼠类(金毛鼠(Chrysochloris asiatica), 盲鼠鼠 (Nannospalax galili), 裸鼠鼠(Heterocephalus glaber), 星鼻鼠(Condylura cristata))检测到55个加速演化的基 因, 功能主要富集在眼睛和皮肤发育相关. 相对较高
的突变速率提示地下环境对生活在其中的哺乳动物的 视力和皮肤功能相关基因发生了选择压力放松, 产生 了与视力下降和皮肤功能退化相关的趋同表型.

海洋环境表现出与陆地环境截然不同的生态环 境, 生活在海洋环境中的海洋哺乳动物, 主要包括鲸目 (Cetacea), 食肉目(Carnivora)的鯺脚亚目(Pinnipedia)和 海牛目(Sirenia)三大类群 ${ }^{[62]}$, 由不同的陆地祖先独立 演化而来, 都经历了从陆地到海洋的剧烈生存环境变 化, 形成了相似的形态结构、生理机能和生态习性以 适应海洋环境, 因此是一个经典的趋同演化的研究系 统 ${ }^{[63-66]}$. Foote等人 ${ }^{[32]}$ 对三类海洋哺乳动物类群共 20 个 物种进行基因组分析, 发现 44 个基因发生了氨基酸平 行替换, 其中 8 个基因还受到了正选择作用, 主要与骨 形成、甲状腺机能立进、心肌形成和调节凝血等相 关, 这些基因功能与海洋环境适应紧密相关. 同年, Zhou等人 ${ }^{[33}$ 对 62 个哺乳动物进行比较基因组分析, 发 现 26 个平行替换基因是三大海洋哺乳动物类群所特 有, 其中多个基因的功能, 包括 $M Y B P C 1$ (骨骼肌收缩), $K C N G 4$ (调节血管收缩), CPOT2(脂肪酸氧化)与海洋哺 乳动物环境适应的趋同表型相关. Chikina研究团队 ${ }^{[19]}$ 则采用与之前报道中不同的检测方法，即通过检测基 因突变速率的方法，对59种哺乳动物的 18049 个同源 编码基因进行分析，检测到大约560个加速演化的基 因, 主要集中在感官系统、肌肉功能、皮肤和结缔组 织、肺功能、脂代谢等和海洋环境适应相关的功能.

食性是连接生物和环境的重要纽带, 因此动物对 食性的适应在动物对环境适应性方面有着重要地位. 具有相同食性的动物在生理结构、消化机制和消化道 微生物组成等方面也表现出趋同特征 ${ }^{[67,68]}$. 最经典的 食性趋同适应演化的案例是食肉目物种中的大熊猫 (Ailuropoda melanoleuca)和小熊猫(Ailurus fulgens)的 食性趋同分子机制研究. 大熊猫(熊科(Ursidae))和小熊 猫(小熊猫科(Ailuridae))属于不同科，大约在 43 个百万 年前发生分歧 ${ }^{[69]}$, 是经历从肉食到植食剧烈转变的类 群，并演化出相同的专食竹子的食性，低营养、高纤 维的竹子占其食物组成的 $90 \%$ 以上 ${ }^{[70]}$. 为适应这种特 殊食性，两种熊猫的前掌都演化出一个特殊结构— 伪拇指, 以帮助抓握竹子 ${ }^{[71]} . \mathrm{Hu}$ 等 $^{[34]}$ 通过比较基因 组分析检测到 70 个基因在两种熊猫中经历了氨基酸替 换趋同，基因功能主要富集在肢端发育、纤毛组装、 蛋白质消化和吸收、视黄醇代谢等通路，这些基因与 
大、小熊猫伪拇指发育和对竹子中必需营养物质的吸 收利用密切相关, 其中 $D Y N C 2 H 1(\mathrm{R} 3128 \mathrm{~K}, \mathrm{~K} 3999 \mathrm{R})$ 和 $P C N T(\mathrm{~S} 2327 \mathrm{P} ， \mathrm{Q} 2458 \mathrm{R})$ 两个基因参与细胞纤毛结构
组装的肢端发育，是调控熊猫伪拇指发育的重要基因 (图2). 此外，在大熊猫和小熊猫基因组的假基因化分 析中，他们还鉴定出 10 个大小熊猫共有的假基因，其

A

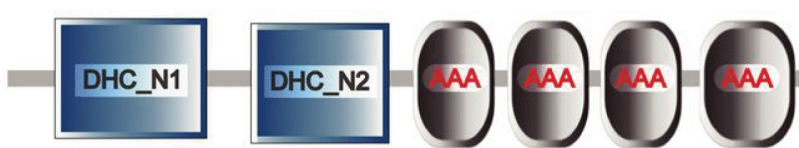

DHC_N1: Dy nein heavy chain, $\mathrm{N}$-terminal region 1, MT: Microtubule-binding stalk of dy nein motor DHC_N2: Dy nein heavy chain, N-terminal region 2, Dy nein_heav y: Dynein heav y chain and region D6 of dy nein motor AAA: ATPases associated with a variety of cellular activ ities

B

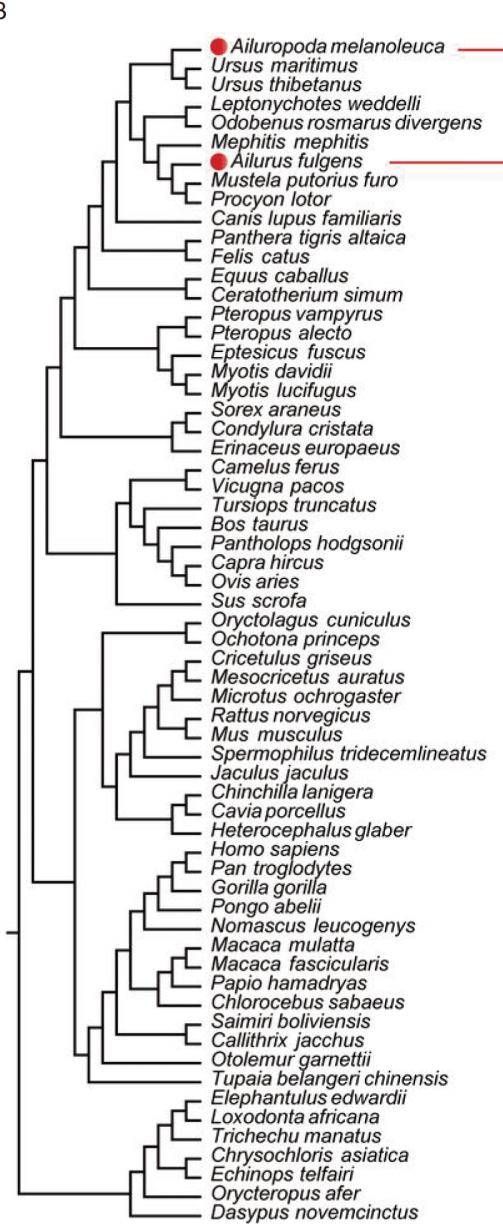

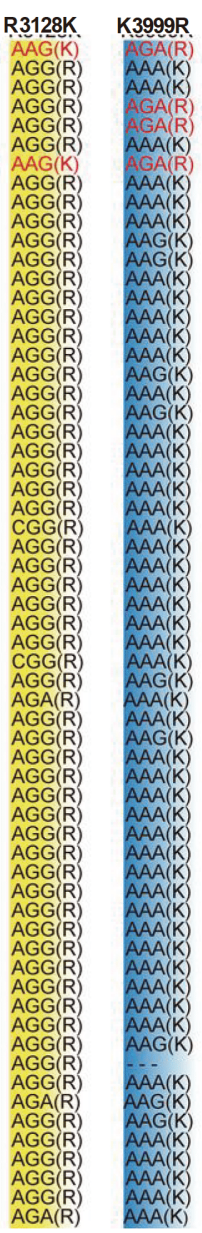

C

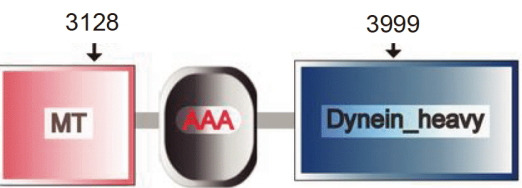

C

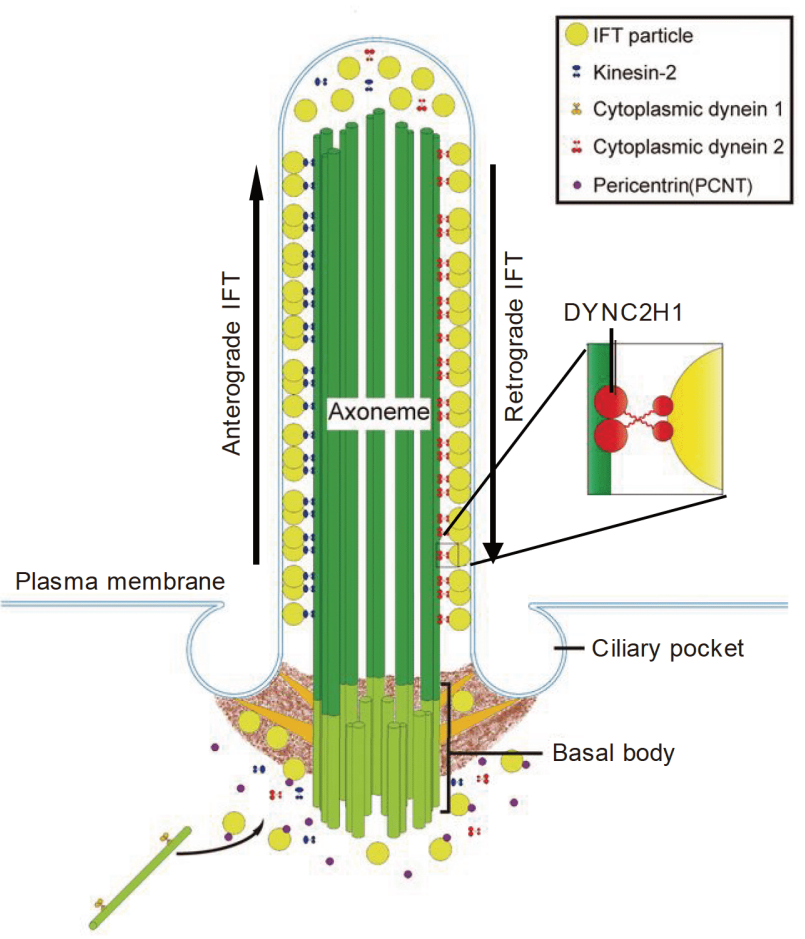

图 2 与大小熊猫伪拇指发育相关的趋同基因. A: 根据SMART数据库获取DYNC2H1蛋白结构域以及两个氨基酸替换位点的 位置; $\mathrm{B}$ : 结合 59 个真兽亚纲物种比较 $D Y N C 2 H 1$ 基因中两个氨基酸替换位点，第一个替换位点(R3128K)只在大小熊猫中发生 变化, 第二个替换位点(K3999R)在大熊猫、小熊猫、海豹和海象中变化; C: DYNC2H1和PCNT蛋白在鞭毛内运输和纤毛发 生过程中的作用. DYNC2H1是细胞质动力蛋白2复合物的核心成分. 引自文献[34]

Figure 2 Adaptively convergent genes closely related with limb development. A: Structural domains of DYNC2H1 protein and the locations of two convergent amino acid sites. The structural domain annotation derives from the SMART database. B: Comparison of two convergent amino acid substitutions of DYNC2H1 gene among the genomes of 59 Eutherian species and the gene fragments of three other Eutherian species (Ursus thibetanus, Mephitis mephitis, and Procyon lotor). The first convergent site is R3128K and the amino acid K only occurs in giant and red pandas. The second convergent site is K3999R and the amino acid R only occurs in giant and red pandas, Weddell seal, and walrus. C: Roles of DYNC2H1 and PCNT proteins in IFT and ciliogenesis. DYNC2H1 is a core component of cytoplasmic dynein 2 complex. Cited from Reference [34] 
中包括感知肉味的鲜味受体基因 $T A S 1 R 1$ 和 $T A S 1 R 2$ 的 假基因化. 这项研究从氨基酸趋同演化、营养物质代 谢通路及假基因化等多个层面揭示了大熊猫和小熊猫 形态性状(如伪拇指)和生理性状(如特化食物竹子中必 须营养物质的利用)趋同的适应分子机制，为趋同演化 分子机制这一演化生物学热点问题的揭示奠定了里程 碑式的基础.

与大小熊猫食性转变正好相反, 海洋哺乳动物鲸 类经历了从植食性到肉食性的剧烈转变 ${ }^{[72]}$. Wang等 人 $^{[73]}$ 利用 10 个鲸类基因组，检测到蛋白酶 $C T R C(\mathrm{I} 4 \mathrm{~V})$, 脂肪酶CYP7A1(R190K, $\mathrm{N} 208 \mathrm{H})$ 和PNLIP(I69L)三个基 因在肉食性鲸类和陆地食肉目动物之间出现了氨基酸 平行替换. 而Meyer等人 ${ }^{[35]}$ 通过比较海洋哺乳动物和 陆生哺乳动物基因组数据还发现 $P O N 1$ 基因在所有海 洋哺乳动物类群中丢失, 而在陆地哺乳动物基因组中 完整保留, 推测与海洋哺乳动物的食物中 $\omega-6$ 多不饱 和脂肪酸总量减少有关. 该项研究也提出选择压力放 松而非环境适应性演化，也可以引起表型趋同。以上 的研究都揭示了海洋哺乳动物与陆生哺乳动物在肉食 性转变过程中的趋同演化分子基础. 而Kim等人 ${ }^{[74]}$ 将 肉食性动物类群(食肉目猫科和熊科以及鲸偶蹄目虎 鲸)与其他食性, 即植食性和杂食性的动物类群进行比 较基因组分析, 发现 $E M B$ 基因在所有肉食性类群中出 现独有的氨基酸趋同替换(A269V)。该基因主要影响 运动神经元的生长和神经肌肉间联结，推测该基因的 趋同演化和肉食性动物的捕食行为相关. 此外, 在肉 食性类群中还检测到与植物源毒素解毒相关的葡萄糖 醛酸基转移酶(UDP-glucuronosyltrans-ferase，UGT)基 因家族显著收缩，推测这与肉食性类群食物组分中缺 少植物紧密相关. 有意思的是, 基因丢失趋同现象也 在肉食和植食的分子趋同演化研究中发现. Hecker等 人 $^{[37]}$ 在哺乳动物中的 5 个独立演化出肉食性的枝系中 检测到 44 个基因发生趋同丢失，且已有研究报道其中 的鲜味受体基因 TASIR1，TAS1R2和PKD $2 L 1$ 以及解毒 基因UGT1A6的丢失与肉食性动物食性相关 ${ }^{[74]}$, 研究 中新发现了 4 个与食性相关的基因在肉食性动物中趋 同丢失，包括控制食欲和维持血糖水平的 INSL 5 和 $R X F P 4$, 植物原毒素解毒基因 $N R 113$, 以及先天免疫基 因 NOX1. 这 4 个基因的功能丧失与肉食性哺乳动物食 物组成和不规律进食行为等食性特化表型相关. 同时, 在哺乳动物中的 6 个独立演化出植食性的枝系中检测
到37个基因发生趋同丢失，研究中新发现了两个基因 $S Y C N$ 和PNLIPRP 1 的趋同丢失, 这可能与提高食物中 甘油三酯的消化吸收效率以及持续性胰蛋白酶的分泌 辅助消化相关, 从而影响植食性动物的食物组分和进 食行为.

\section{2 基于非编码区的基因表达调控的分子趋 同演化}

动物基因组中，编码区基因仅占基因组大小的 1\% 10\%，90\%以上由包含各种调控基因表达元件的 非编码区序列组成 ${ }^{[75,76]}$. 越来越多的研究显示, 调控 区序列变化比编码区更能影响生物生理结构、表型甚 至行为的改变 ${ }^{[77]}$. 鉴于此, 进化生物学家开始关注与 研究非编码区调控基因表达所引起的表型趋同的分子 机制.

在非编码区基因水平研究远缘生物趋同演化分子 机制的最典型案例是2019年发表的以平胸总目鸟类 (Ratites) 为研究对象来解析鸟类飞行能力丧失的遗传 基础的报道. 该类群由多次独立演化形成, 包括鸟鸟 (Struthio camelus), 几维鸟(Apteryx spp.), 美洲鸟 (Rhea Americana), 食火鸡(Casuarius casuarius)和鸸鹋(Dromaius novaehollandiae)等, 在生理结构上缺少龙骨突, 难以附着胸肌, 前肢短小甚至缺失, 腿部发达, 腿骨无 气室结构等多个与飞行能力丧失有关的性状, 是研究 鸟类飞行能力丧失的趋同演化的良好模型. Sackton等 人 ${ }^{[38]}$ 对包括 9 个平胸目鸟类在内的 44 种鸟类进行全基 因组分析，他们在编码区基因中并没有篮选到与飞行 能力丧失相关的平行替换或正选择基因，而在非编码 区中发现了2355个非外显子保守元件(conserved nonexonic elements, CNEE)在平胸目中特异加速演化. 功 能富集分析发现, 部分加速演化的CNEE定位在和肢 体发育相关的关键基因附近，包括 $T B X 5, D A C H 1$, $P A X 9, I R X$ 等. 其中已有研究报道, 编号 $\mathrm{mCE} 967994$ 元 件定位在与细胞增殖相关的 $T E A D 1$ 基因内含子区域, 该元件在鸡的前肢发育过程中起持续调控作用，然而 该研究显示，这个元件在可以飞行的鸟类中是保守的， 但在平胸目类群中表现为趋同加速演化. 通过进一步 功能验证发现, 平胸目的该元件不具备启动子活性, 因此提示该调控元件加速演化可能与平胸目鸟类丧失 飞行能力趋同表型相关. 
除此之外, 也有研究者发现在地下哺乳类群中(盲 鼠鼠(Nannospalax galili), 裸鼠鼠(Heterocephalus glaber), 金毛鼠(Chrysochloris asiatica), 星鼻鼠(Condylura cristata))，与眼发育相关基因Pax6的增强子区域存在 演化速率加快的信号, 突变的累积影响了P ax6 基因表 达调控和晶状体发育, 这种变化和地下哺乳动物视觉 在选择压力放松导致视觉功能衰退的趋同表型密切相 关 $^{[29]}$.

在果蝇类群中也发现，两个在 40 个百万年分歧的 果蝇物种(Drosophila sechellia和D. ezoana) 的幼虫与 各自近缘物种(分别为D. melanogaster和D. littoralis/ D. virilis)的幼虫相比，都表现出表皮毛状体结构缺失 的相同表型. Frankel等人 ${ }^{[15]}$ 针对与毛状体分化相关的 主要基因Shavenbaby $(S v b)$ 的上游启动子区进行结构和 功能分析发现，虽然两个毛状体缺失物种和毛状体正 常物种的 $S v b$ 基因上游表达调控区域都含有7个增强子 结构, 但毛状体缺失物种的第3增强子功能上表现为趋 同缺失, 不能有效启动下游基因的表达, 从而产生了相 同表型 ${ }^{[15]}$.

\section{3 基于基因表达模式的分子趋同演化}

相对于遗传固定表型，许多性状是复杂和具有弹 性的, 是对环境变化的高度响应以及多个基因相互作 用综合表达的结果 ${ }^{[39]}$ ，由于基因表达差异具有时间空 间特异性，基因功能普遍与不同时空条件下基因的表 达模式有相关性，从基因的表达模式解析不同生物间 趋同特征是另一种独特的研究视角. 基于转录组高通 量测序技术，能够获取生物特定组织或细胞所有RNA 的集合即转录组数据, 反映物种全基因在不同发育阶 段以及环境胁迫下的生理状态 ${ }^{[78]}$. 对转录组数据的解 读, 为研究基因的表达调控和阐明基因功能提供强有 力的证据，有助于从新的角度揭示物种趋同表型的分 子机制 ${ }^{[79]}$.

2014年邓小弓等人 ${ }^{[31]}$ 利用转录组数据从氨基酸 位点变化和基因表达量水平研究高原鼠鼠和裸鼠鼠地 下环境适应的分子趋同机制，鉴定出54个基因具有趋 同演化位点，其中 13 个基因与肌肉、血液循环、氧代 谢、脂类代谢、能量平衡、营养物质运输及眼睛、四 肢发育和听觉等功能相关; 通过基因表达量的分析检 测出在两种地下鼠中都发生上调的基因中，20个基因
与心脏功能、红细胞功能、有氧呼吸、肌肉骨骼功 能、DNA损伤修复、免疫及生物节律相关，虽然两种 方法所䇻选到的功能基因与地下鼠低氧适应、能量代 谢与平衡及挖掘器官或组织发育等功能关联, 但是并 没有基因上的重叠. 进一步对同源基因进行分层聚类 分析显示, 虽然高原鼠鼠和小鼠、裸鼠鼠和豚鼠的系 统发育关系更近，但是表达量特征分析结果却显示两 种地下鼠更相似, 两种地上鼠更相似, 说明了地下鼠 在基因表达上的趋同效应.

除此之外, Pankey等人 ${ }^{[16]}$ 以头足类动物中的夏威 夷短尾乌贼(乌贼目)和剑尖枪乌贼(枪型目)为研究对 象，对两种乌贼独立起源的体内发光器官进行趋同演 化分子机制的研究. 研究团队通过分析包括发光器官 以及 5 个同源器官的转录组数据, 发现两种乌贼并不 同源的发光器官的表达模式比同源器官的表达模式更 相似. 有意思的是, 这种相似性还能用于对未知转录组 数据信息进行预测. 例如, 如果用一种乌贼的发光器转 录组数据建立一个模型, 那么这个模型能够成功地将 另一种乌贼的发光器转录组从随机挑选的不同组织基 因混合成的“伪转录组”中识别出来，识别的成功率甚 至高于一些同源器官的识别. 这种非同源的趋同器官 具有相似和可预测的转录组, 为生物演化提供新的视 角和方向. 因此, 这项研究提示这两种乌贼在演化过 程中, 发光器官的产生并非完全是通过编码区基因的 功能改变而产生, 更可能是依靠现有的基因, 甚至是 一组基因模块，来进行修正和组合，从而产生新的 功能.

另外一个比较有意思的案例是关于社会性昆虫蚂 蚁(蜜蜂)等群体的生殖等级分化相关的调控机制研 究 ${ }^{[40]}$. 早期研究认为, 生殖等级分化起源于蚂蚁(蜜蜂) 的共同祖先，通过祖先基因的调控网络(gene regulatory network, GRN)影响不同等级类群的发育. Berens 等人 ${ }^{[39]}$ 对火蚁、蜜蜂和黄蜂三种膜翅目昆虫的蚁(蜂) 后和工蚁(蜂)个体进行转录组分析, 发现这三个物种 的相同生殖等级类群的基因表达模式高度相似. Qiu 等人 ${ }^{[40]}$ 对具有明确生殖等级的属于三个亚科的 5 个蚂 蚁物种(顶切叶蚁 (Acromyrmex echinatior), 法老蚁 (Monomorium pharaonis), 小麻臭蚁(Linepithema humile), 红火蚁 (Solenopsis invicta) 和黑毛蚁 (Lasius niger)) 的大脑组织进行转录组测序和基因表达分析, 发 现了一系列与生殖等级相关并在演化过程中表现出同 
方向、程度类似的等级差异表达基因. 更有意思的是， 研究人员还比较了同样具有生殖等级分化系统的蜜蜂 类群, 也检测到和蚂蚁等级分化相同的差异表达基因. 这意味着蚂蚁和蜜蜂的等级系统经历了趋同演化. 这 个研究重构了各蚂蚁物种等级分化的祖先基因调控网 络, 并开启了进一步挖掘与调控等级分化相关的核心 基因和作用机制的大门.

\section{4 基于肠道微生物水平的分子趋同演化}

动物肠道微生物组是指存在于动物肠道的庞大微 生物, 这群微生物作为寄主依靠宿主肠道生存, 同时参 与宿主发育、免疫、营养代谢等多个生理过程, 被誉为 宿主的“第二套”基因组, 在宿主生存演化过程中起到重 要作用 ${ }^{[80]}$. 随着测序技术的发展, 宏基因组测序技术可 以高通量获取肠道微生物组的数据信息, 对其组分、结 构、功能等进行分析来解析动物的适应性演化 ${ }^{[68]}$.

早在2011年, Muegge等人 ${ }^{[14]}$ 对来自哺乳动物不同 食性的 10 个目共 33 个物种的粪便样品进行 $16 \mathrm{~S}$ rRNA 以及宏基因组测序分析, 发现植食性、肉食性和杂食 性三种不同食性的动物在肠道微生物组分构成明显不 同, 微生物功能富集也有明显区分. 植食性动物肠道微 生物在氨基酸合成通路富集, 而肉食性动物则富集在 氨基酸降解通路, 不仅说明食性对于肠道微生物的重 要影响, 也提示相同食性物种的肠道微生物的趋同演 化. 接下来, Delsuc等人 ${ }^{[36]}$ 结合Muegge等人 ${ }^{[14]}$ 的数据, 增加了蚁食性的动物粪便样品, 覆盖哺乳动物 12 个目 共47个物种的粪便样品进行 $16 \mathrm{~S}$ rRNA测序分析, 结果 显示肉食性哺乳动物肠道微生物以厚壁菌门为主, 植 食性哺乳动物以厚壁菌门和拟杆菌门占主要成分, 杂 食性肠道微生物构成则与植食性比较相似, 蚁食性哺 乳动物以变形菌门占主要成分, 而且通过 $\beta$ 多样性网 络聚类分析, 发现肉食性、植食性和杂食性各自聚在 一起，而食性特化的蚁食性哺乳动物披毛目食蚁兽、 食肉目土狼、管齿目土豚和单孔目短吻针鼠的肠道微 生物组分聚类在一起, 这些结果提示肠道微生物在特 定食性物种间表现出趋同特性.

Zhang等人 ${ }^{[28]}$ 则采用宏基因组学方法关注高海拔 环境适应过程中哺乳动物的肠道微生物是否存在趋同 演化. 研究团队首先检测了青藏高原反刍动物牦牛、 藏绵羊的瘤胃微生物组的发酵产物, 发现挥发性脂肪
酸(微生物组发酵产生的供能物质, 包括乙酸、丙酸和 丁酸)的产量高于低海拔的牛和绵羊, 而甲烷(瘤胃发 酵的副产物, 无法被宿主利用, 导致能量浪费)产量相 对较低. 两个高海拔反刍动物都产出高比例挥发性脂 肪酸, 提示它们的瘤胃微生物组可能存在趋同演化模 式. 研究人员进一步对高海拔牛牛、藏绵羊和低海拔 牛、绵羊的瘤胃微生物组进行宏基因组测序, 聚类结 果显示两个高海拔反刍动物的肠道微生物在群落结构 上聚在一起, 而且高海拔牛牛和藏绵羊瘤胃微生物组 在挥发性脂肪酸合成代谢通路上显著富集(图3). 以上 结果表明, 高原反刍动物的瘤胃微生物在组分及功能 上的趋同适应. 此外, 通过比较牦牛和低海拔牛的瘤 胃黏膜转录组发现, 牦牛短链脂肪酸运输和吸收相关 的36个基因显著上调, 说明高原动物自身也能够更好 地吸收和利用瘤胃发酵产生的短链脂肪酸获取能量, 提示宿主和肠道微生物组之间发生了协同演化. 该研 究通过宿主黏膜转录组及其消化道微生物组的分析发 现动物适应高原极端环境过程中宿主和微生物组之间 的协同演化，这不仅揭示了肠道微生物组本身的演化 特性, 也为宿主表型趋同的分子机制提供了全新视角. 这个研究表明, 动物除了在基因组层面的趋同演化外, 在共生消化道微生物组结构和功能的趋同演化是研究 哺乳动物高原适应的另一种新机制, 为动物适应性演 化提供了新的视角 ${ }^{[81]}$.

宏基因组趋同研究目前在宿主食性、营养吸收和 能量代谢等趋同表型的分子水平解析提供了独特的视 角和结论, 作为与宿主共存的“第二套” 基因组, 宏基因 组在宿主生存周期内还参与发育、免疫等多个重要的 生理功能 ${ }^{[80]}$, 宏基因组的趋同研究可为宿主生物的表 型趋同提供更加独特的研究视角和结论.

\section{5 展望}

对趋同表型分子机制研究的关注. 不断催生这个 领域在概念和方法上的发展. Doolittle ${ }^{[13]}$ 曾定义了4种 分子水平的趋同现象: 功能趋同、作用机制趋同、结 构趋同、序列趋同, 进而发展到Zhang和Kumar ${ }^{[41]}$ 以及 Zhang ${ }^{[42]}$ 在早期研究中提出编码氨基酸水平趋同替换 和平行替换的概念并提出相对严格的研究策略和检测 方法. 后续大量基于编码基因的研究都遵循以上定义 的方法进行比较基因组检测，然而鉴于两个枝系间经 


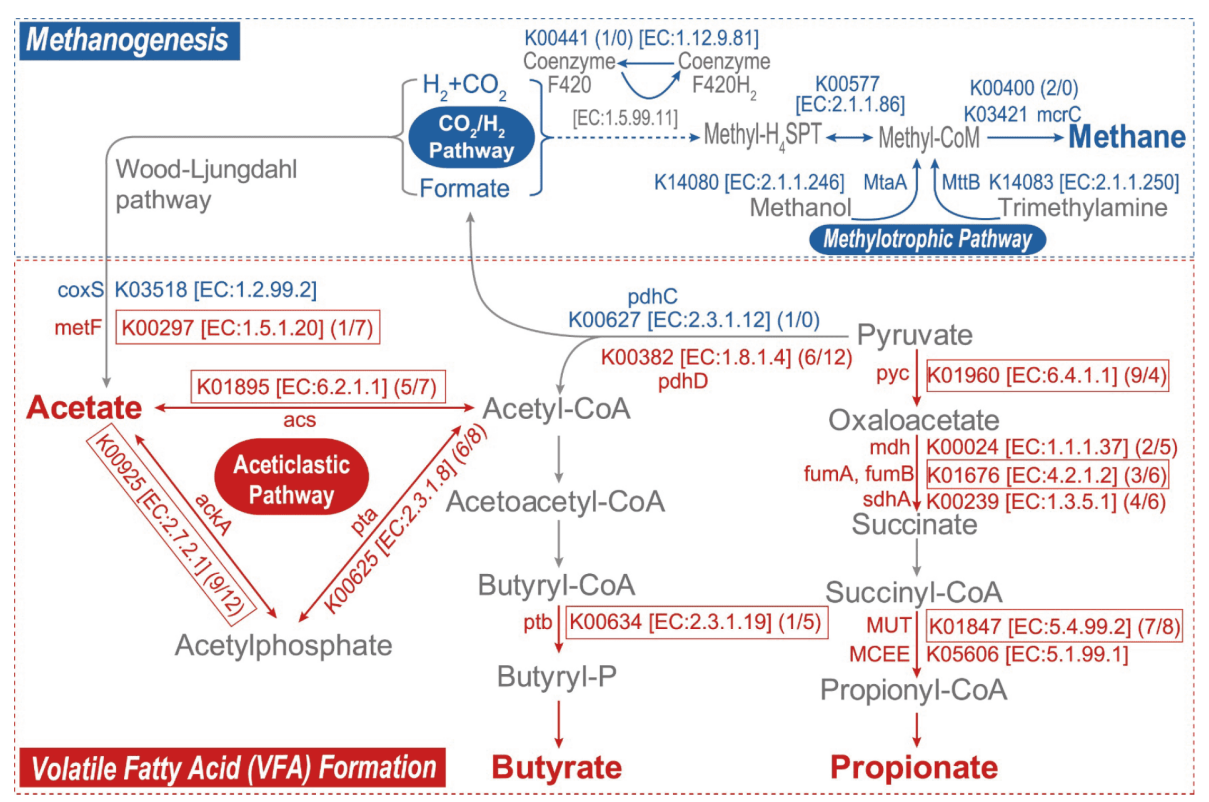

图 3 青藏高原反刍动物(牦牛、藏绵羊)挥发性脂肪酸发酵、甲烷产生代谢通路图. 所有 $\mathrm{KO}, \mathrm{K}, \mathrm{EC}$ 编号以及基因名称均来自 KEGG数据库. 红色: 牦牛的 $\mathrm{KO}$ 富集类别; 红色方框: 牦牛和藏绵羊共有的 $\mathrm{KO}$ 富集类别; 蓝色: 牛的 $\mathrm{KO}$ 富集类别. 6 个快速演化 的酶集中在原核生物的固氮通路中(K00297, K01895, K00925, K01960, K01676和K01847). 引自文献[28]

Figure 3 Reconstruction of the metabolic pathway associated with VFA formation and methanogenesis in Tibetan ruminants. All KO numbers, or K numbers, EC numbers, and gene names obtained from KEGG database. KO categories enriched in yaks are highlighted with red. Boxed KO categories are co-enriched in yaks and T-sheep. KO categories denoted by blue uniquely are enriched in cattle. REG numbers between yaks and cattle and between T-sheep and ordinary sheep are noted in parentheses. Six rapidly evolved enzymes (represented by K00297, K01895, K00925, K01960, K01676, and K01847) were found in the carbon fixation pathways in prokaryotes. Cited from Reference [28]

历独立演化出现完全相同的氨基酸替换机率太低 ${ }^{[41]}$, 除了常用的通过检测基因氨基酸位点祖先状态与现生 状态的变异方法, 研究者们提出可以通过检测编码基 因相对突变速率来鉴定发生趋同事件的基因 ${ }^{[19]}$, 也可 以通过检测序列位点上氨基酸性质是否发生了剧烈改 变, 如替换成极性、正负电荷等特征一致的氨基酸来 判断是否产生了氨基酸水平的趋同或平行变化 ${ }^{[53]}$. Sun等人 ${ }^{[27]}$ 则通过将正选择基因富集到通路的方法进 行趋同演化分析, 提出趋同演化更大程度地体现在功 能上的趋同, 而非特定的基因. 此外, 虽然多数被研究 的物种在亲缘关系上相距较远而不需要排除基因渗透 等原因所造成的氨基酸趋同 ${ }^{[2]}$, 但Liu等人 ${ }^{[12]}$ 提出在经 历适应性辐射的不同物种中, 仍需考虑的是, 由于祖先 多态位点独立固定造成的表型趋同(侧枝演化) ${ }^{[2]}$, 而非 适应性演化驱动的表型趋同 ${ }^{[22]}$. 这些都在不停地拓展 和完善分子趋同演化研究领域的研究方法和思路, 虽 然Parker等人 ${ }^{[20]}$ 的结果受到多方质疑, 但从另一个角 度也说明, 正是由于分子趋同作为研究热点, 受到来 自各方的持续关注, 从研究思路、验证方法、模型等
多方面进一步推动该领域分析方法的不断推陈出新, 并衍生出针对编码基因趋同的概念延伸和检测手段的 更新，为基因组时代下分子水平趋同研究打下坚实的 理论基础.

此外还注意到, 早期研究主要局限在编码基因研 究, 而且是对已知趋同候选基因进行多物种之间的比 较. 随着高通量测序技术的高速发展, 各种组学所需 研究材料获取门槛降低, 在大数据组学环境下, 分子 趋同演化研究已不再局限于已知候选单基因的比较, 研究者可以获取更多的数据信息, 如基因组中不同结 构(编码区、表达调控区)、基因表达时空差异(转录 组)以及与宿主协同演化的肠道微生物(宏基因组). 通 过比较组学的方法, 从更宽广的范围和角度对目的性 状相关分子证据进行篮查, 从基因丢失趋同、基因表 达调控趋同、基因表达模式趋同、宏基因组组分功能 趋同等多个角度完善生物表型趋同的分子证据. 另一 方面, CRISPR/Cas9等基因编辑技术的高速发展, 为分 子水平趋同证据的功能验证提供了更先进的验证思 路, 不仅仅局限于蛋白和细胞水平, 通过构建突变个体 
和品系能更好地说明分子变化带来的表型变化. 越来 越多的编码序列趋同和表达调控趋同的研究结果得到 细胞水平甚至个体水平的验证，也为证实从分子趋同 到表型趋同关键一步提供了重要证据. 此外, 随着 Hi-C，ChIP-seq及ATAC-seq等测序技术的发展，趋同 演化有望在表观遗传组学方面有所突破.

在基因组时代下，基于多组学水平的趋同演化研 究已经从编码基因、转录表达、网络调控、协同演 化等多个层次为人们展现了令人惊艳的结果, 多个层 级间协同分析揭示分子趋同的报道也已经出现，对多
层级遗传信息的深度挖掘为揭示生物趋同演化的分 子证据不断提出新问题、新视角、新答案. 目前已有 大量生物基因组数据被测序获取(https://vertebrategenomesproject.org), 这个数量还将不断增加, 可分析 数据的增多为分子趋同研究提供了更加丰富的研究 材料, 也可以提供更加准确的研究结果. 相应地, 面对 海量的组学数据, 也将为计算能力、分析策略、研究 模型等提出新的挑战, 分子水平的趋同演化在方法、 材料、概念上的交互迭代, 会不断为这个领域谱写新 的篇章.

\section{参考文献}

1 Losos J B. Convergence, adaptation, and constraint. Evolution, 2011, 65: 1827-1840

2 Stern D L. The genetic causes of convergent evolution. Nat Rev Genet, 2013, 14: 751-764

3 Storz J F. Causes of molecular convergence and parallelism in protein evolution. Nat Rev Genet, 2016, 17: 239-250

4 Hoy R R. Convergent evolution of hearing. Science, 2012, 338: 894-895

5 Grant P R, Grant B R, Markert J A, et al. Convergent evolution of darwin's finches caused by introgressive hybridization and selection. Evolution, 2004, 58: 1588-1599

6 Norberg U M. Evolutionary convergence in foraging niche and flight morphology in insectivorous aerial-hawking birds and bats. Ornis Scandinavica, 1986, 17: 253-260

7 Lee J H, Hiller M. Genome-wide Screens for Molecular Convergent Evolution in Mammals. Evolutionary Biology: Self/nonself Evolution, Species and Complex Traits Evolution, Methods and Concepts. Switzerland: Springer International Publishing, 2017. 297-312

8 Wroe S, Milne N. Convergence and remarkably consistent constraint in the evolution of carnivore skull shape. Evolution, 2007, 61: 1251-1260

9 Delsuc F, Douzery E. Recent Advances and Future Prospects in Xenarthran Molecular Phylogenetics. The Biology of the Xenarthra. Gainesville: University Press of Florida, 2008

10 Mahler D L, Weber M G, Wagner C E, et al. Pattern and process in the comparative study of convergent evolution. Am Natist, 2017, 190: S13S28

11 Rosenblum E B, Parent C E, Brandt E E. The molecular basis of phenotypic convergence. Annu Rev Ecol Evol Syst, 2014, 45: 203-226

12 Liu Z, Bai J, Shi P. Genetic and lutionary mechanisms of convergent phenotypes in animals (in Chinese). Sci Sin Vitae, 2019, 49: 338-344 [刘振, 白婧, 施鹏. 动物趋同表型分子遗传和演化机制的研究进展. 中国科学: 生命科学, 2019, 49: 338-344]

13 Doolittle R F. Convergent evolution: The need to be explicit. Trends Biochem Sci, 1994, 19: 15-18

14 Muegge B D, Kuczynski J, Knights D, et al. Diet drives convergence in gut microbiome functions across mammalian phylogeny and within humans. Science, 2011, 332: 970-974

15 Frankel N, Wang S, Stern D L. Conserved regulatory architecture underlies parallel genetic changes and convergent phenotypic evolution. Proc Natl Acad Sci USA, 2012, 109: 20975-20979

16 Pankey M S, Minin V N, Imholte G C, et al. Predictable transcriptome evolution in the convergent and complex bioluminescent organs of squid. Proc Natl Acad Sci USA, 2014, 111: E4736-E4742

17 Zou Z, Zhang J. Are convergent and parallel amino acid substitutions in protein evolution more prevalent than neutral expectations? Mol Biol Evol, 2015, 32: 2085-2096

18 Zou Z, Zhang J. No genome-wide protein sequence convergence for echolocation. Mol Biol Evol, 2015, 32: 1237-1241

19 Chikina M, Robinson J D, Clark N L. Hundreds of genes experienced convergent shifts in selective pressure in marine mammals. Mol Biol Evol, 2016, 33: 2182-2192

20 Parker J, Tsagkogeorga G, Cotton J A, et al. Genome-wide signatures of convergent evolution in echolocating mammals. Nature, 2013, 502: 228- 
231

21 Liu Z, Qi F Y, Xu D M, et al. Genomic and functional evidence reveals molecular insights into the origin of echolocation in whales. Sci Adv, 2018, 4: eaat 8821

22 Lee J H, Lewis K M, Moural T W, et al. Molecular parallelism in fast-twitch muscle proteins in echolocating mammals. Sci Adv, 2018, 4: eaat9660

23 Yu L, Wang G D, Ruan J, et al. Genomic analysis of snub-nosed monkeys (Rhinopithecus) identifies genes and processes related to high-altitude adaptation. Nat Genet, 2016, 48: 947-952

24 Wang G D, Fan R X, Zhai W, et al. Genetic convergence in the adaptation of dogs and humans to the high-altitude environment of the tibetan plateau. Genome Biol Evol, 2014, 6: 2122-2128

25 Ge R L, Cai Q, Shen Y Y, et al. Draft genome sequence of the tibetan antelope. Nat Commun, 2013, 4: 1858

Wang Z, Ma T, Ma J, et al. Convergent evolution of SOCS4 between yak and tibetan antelope in response to high-altitude stress. Gene, 2015, 572: 298-302

27 Sun Y B, Fu T T, Jin J Q, et al. Species groups distributed across elevational gradients reveal convergent and continuous genetic adaptation to high elevations. Proc Natl Acad Sci USA, 2018, 115: E10634-E10641

28 Zhang Z, Xu D, Wang L, et al. Convergent evolution of rumen microbiomes in high-altitude mammals. Curr Biol, 2016, 26: 1873-1879

29 Partha R, Chauhan B K, Ferreira Z, et al. Subterranean mammals show convergent regression in ocular genes and enhancers, along with adaptation to tunneling. eLife, 2017, 6: e25884

30 Shao Y, Li J X, Ge R L, et al. Genetic adaptations of the plateau zokor in high-elevation burrows. Sci Rep, 2015, 5: 17262

31 Deng X G, Wang K, Zhang S D, et al. Transcriptomatic determination of convergent evolution between plateau zokors (Eospalax baileyi) and naked mole rats (Heterocephalus glaber) (in Chinese). Acta Theriol Sin, 2014, 34: 129-137 [邓小弓, 王枋, 张守栋, 等. 利用转录组数据分析高 原鼠鼠和裸鼠鼠基因的趋同进化. 兽类学报, 2014, 34: 129-137]

32 Foote A D, Liu Y, Thomas G W C, et al. Convergent evolution of the genomes of marine mammals. Nat Genet, 2015, 47: 272-275

33 Zhou X, Seim I, Gladyshev V N. Convergent evolution of marine mammals is associated with distinct substitutions in common genes. Sci Rep, 2015, 5: 16550

$34 \mathrm{Hu} \mathrm{Y,} \mathrm{Wu} \mathrm{Q,} \mathrm{Ma} \mathrm{S,} \mathrm{et} \mathrm{al.} \mathrm{Comparative} \mathrm{genomics} \mathrm{reveals} \mathrm{convergent} \mathrm{evolution} \mathrm{between} \mathrm{the} \mathrm{bamboo-eating} \mathrm{giant} \mathrm{and} \mathrm{red} \mathrm{pandas.} \mathrm{Proc} \mathrm{Natl} \mathrm{Acad}$ Sci USA, 2017, 114: 1081-1086

35 Meyer W K, Jamison J, Richter R, et al. Ancient convergent losses of Paraoxonase 1 yield potential risks for modern marine mammals. Science, 2018, 361: 591-594

36 Delsuc F, Metcalf J L, Wegener Parfrey L, et al. Convergence of gut microbiomes in myrmecophagous mammals. Mol Ecol, 2014, 23: 13011317

37 Hecker N, Sharma V, Hiller M. Convergent gene losses illuminate metabolic and physiological changes in herbivores and carnivores. Proc Natl Acad Sci USA, 2019, 116: 3036-3041

38 Sackton T B, Grayson P, Cloutier A, et al. Convergent regulatory evolution and loss of flight in paleognathous birds. Science, 2019, 364: 74-78

39 Berens A J, Hunt J H, Toth A L. Comparative transcriptomics of convergent evolution: Different genes but conserved pathways underlie caste phenotypes across lineages of eusocial insects. Mol Biol Evol, 2015, 32: 690-703

40 Qiu B, Larsen R S, Chang N C, et al. Towards reconstructing the ancestral brain gene-network regulating caste differentiation in ants. Nat Ecol Evol, 2018, 2: 1782-1791

41 Zhang J, Kumar S. Detection of convergent and parallel evolution at the amino acid sequence level. Mol Biol Evol, 1997, 14: 527-536

42 Zhang J. Parallel adaptive origins of digestive rnases in asian and african leaf monkeys. Nat Genet, 2006, 38: 819-823

43 Li G, Wang J, Rossiter S J, et al. The hearing gene prestin reunites echolocating bats. Proc Natl Acad Sci USA, 2008, 105: 13959-13964

44 Liu Y, Cotton J A, Shen B, et al. Convergent sequence evolution between echolocating bats and dolphins. Curr Biol, 2010, 20: R53-R54

45 Davies K T J, Cotton J A, Kirwan J D, et al. Parallel signatures of sequence evolution among hearing genes in echolocating mammals: An emerging model of genetic convergence. Heredity, 2012, 108: 480-489

46 Shen Y Y, Liang L, Li G S, et al. Parallel evolution of auditory genes for echolocation in bats and toothed whales. PLoS Genet, 2012, 8: e1002788

47 Liu Z, Li S, Wang W, et al. Parallel evolution of kcnq4 in echolocating bats. PLoS ONE, 2011, 6: e26618 
48 Liu Y, Han N, Franchini L F, et al. The voltage-gated potassium channel subfamily kqt member 4 (kcnq4) displays parallel evolution in echolocating bats. Mol Biol Evol, 2012, 29: 1441-1450

49 Li Y, Liu Z, Shi P, et al. The hearing gene prestin unites echolocating bats and whales. Curr Biol, 2010, 20: R55-R56

50 Dallos P, Fakler B. Prestin, a new type of motor protein. Nat Rev Mol Cell Biol, 2002, 3: 104-111

51 Liu Z, Qi F Y, Zhou X, et al. Parallel sites implicate functional convergence of the hearing gene prestin among echolocating mammals. Mol Biol Evol, 2014, 31: 2415-2424

52 Thomas G W C, Hahn M W. Determining the null model for detecting adaptive convergence from genomic data: A case study using echolocating mammals. Mol Biol Evol, 2015, 32: 1232-1236

53 Rey C, Guéguen L, Sémon M, et al. Accurate detection of convergent amino-acid evolution with pcoc. Mol Biol Evol, 2018, 35: 2296-2306

54 Starr T N, Thornton J W. Epistasis in protein evolution. Protein Sci, 2016, 25: 1204-1218

55 Pollock D D, Thiltgen G, Goldstein R A. Amino acid coevolution induces an evolutionary stokes shift. Proc Natl Acad Sci USA, 2012, 109: E1352-E1359

56 Beall C M. Two routes to functional adaptation: Tibetan and andean high-altitude natives. Proc Natl Acad Sci USA, 2007, 104: 8655-8660

57 Beall C M, Cavalleri G L, Deng L, et al. Natural selection on EPAS1 (HIF2) associated with low hemoglobin concentration in Tibetan highlanders. Proc Natl Acad Sci USA, 2010, 107: 11459-11464 myanmar snub-nosed monkey rhinopithecus strykeri. PLoS ONE, 2012, 7: e37418

60 mammals: A comparative study of three superorders. Mol Biol Evol, 2018, 35: 2544-2559

64 McGowen M R, Grossman L I, Wildman D E. Dolphin genome provides evidence for adaptive evolution of nervous system genes and a molecular rate slowdown. Proc R Soc B-Biol Sci, 2012, 279: 3643-3651

74 Kim S, Cho Y S, Kim H M, et al. Comparison of carnivore, omnivore, and herbivore mammalian genomes with a new leopard assembly. Genome Biol, 2016, 17: 211

75 Elgar G, Vavouri T. Tuning in to the signals: Noncoding sequence conservation in vertebrate genomes. Trends Genet, 2008, 24: 344-352

Hardison R. Conserved noncoding sequences are reliable guides to regulatory elements. Trends Genet, 2000, 16: 369-372

Wray G A. The evolutionary significance of cis-regulatory mutations. Nat Rev Genet, 2007, 8: 206-216

Wang Z, Gerstein M, Snyder M. Rna-seq: A revolutionary tool for transcriptomics. Nat Rev Genet, 2009, 10: 57-63

Schulze A, Downward J. Navigating gene expression using microarrays: A technology review. Nat Cell Biol, 2001, 3: E190-E195

Carroll I M, Threadgill D W, Threadgill D S. The gastrointestinal microbiome: A malleable, third genome of mammals. Mamm Genome, 2009, 
20: $395-403$

81 Wei F W. New angle to study the adaptive evolution: Animal gut microbiome (in Chinese). Sci Sin Vitae, 2016, 46: 1338-1340 [魏辅文. 动物适 应性进化研究的新视角: 动物肠道微生物组. 中国科学: 生命科学, 2016, 46: 1338-1340]

82 Li Y Y, Liu Z, Qi F Y, et al. Functional effects of a retained ancestral polymorphism in Prestin. Mol Biol Evol, 2017, 34: 88-92

\title{
Recent progress in convergent molecular evolution of animals based on multi-omics studies
}

\author{
CHENG Shao Chen, WANG Xiao Ping \& YU Li \\ State Key Laboratory for Conservation and Utilization of Bio-Resources in Yunnan \& School of Life Sciences, \\ Yunnan University, Kunming 650091, China
}

\begin{abstract}
Molecular evidence for phenotypic convergence has been a hot topic in convergent evolution research. High-throughput sequencing techniques produce multi-omics data, providing a large number of research materials and more diverse perspectives for convergent molecular evolution. The concept of molecular convergence extends from the convergence of amino acid replacement coding genes to that of gene loss, expression regulation, expression patterns, and metagenomic convergence. Based on different concepts, materials, and purposes, the methods of molecular convergence are continually expanding and being updated. This paper reviews the recent progress in convergent molecular evolution of animals based on multi-omics studies in the genomic era. The future research directions in this field are also investigated.
\end{abstract}

convergent evolution, genomic convergence, expression regulation convergence, metagenomic convergence doi: $10.1360 /$ SSV-2019-0101 